\title{
A competência informacional e a graduação em Biblioteconomia na Puc- Campinas: uma análise de 2008
}

\section{Leandro dos Santos Nascimento}

\author{
Bibliotecário do Escritório Lemos e Associados \\ advocacia.
}

Vera Silvia Marão Beraquet

\begin{abstract}
Ph.D. em Biblioteconomia e Estudos da Informação pela Loughborough University, Inglaterra. Professora da Faculdade de Biblioteconomia da PUC-Campinas.
\end{abstract}

Esta pesquisa buscou identificar a contribuição do Curso de Biblioteconomia da PUC-Campinas para $o$ desenvolvimento da competência em informação, observando o nível desta habilidade nos alunos ingressantes e formandos, expondo o cenário desta competência e verificando a aplicação desta habilidade em seus trabalhos. O levantamento dos dados foi obtido a partir de um questionário. Os resultados foram comparados à pesquisa de Campello e Abreu (2005) e ao modelo proposto por Kuhlthau (1996), verificando-se melhora significativa no âmbito da questão.

Palavras-chave: Aprendizagem; Competência em Informação; Information Literacy; Universidade; Bibliotecário; Docente.

\section{The information literacy and library PUC-Campinas graduation: an analysis of the 2008.}

This research aimed at identifying the contribution of the Course in Library Science of PUC Campinas in the development of competence in information. For that, the level of skills in newcomers as well as recently graduated students was observed by exposing the scenario of this competence and checking the application of that skill in their works. The survey was done using a questionnaire. The results were compared with the research of Campello 
and Abreu (2005) and the model proposed by Kuhlthau (1996), showing significant improvement in the ambit of the subject.

Keywords: Learning; Information Competence; Information Literacy; University; Librarian; Teacher.

Recebido em 24.08.2009 Aceito em 04.12.2009

\section{Introdução}

O constante desenvolvimento da sociedade requer de seus membros diversas competências para que se mantenham atualizados e se tornem cidadãos conscientes. Com a crescente valorização da informação e do conhecimento, Seabra (1998 apud DUDZIAK 2001, p. 3) aponta que "o conhecimento passa a ter papel fundamental nas relações de produção e, por conseqüência, na ordem e no poder mundiais", e Dudziak (2001, p. 3) indica que "[...] o valor que o conhecimento agrega é fator determinante, superando cada vez mais o trabalho e a matéria prima. Faz-se necessário preparar o indivíduo para viver numa era caracterizada por uma grande teia de relações e conexões".

Diante de tal cenário, no qual a informação e o conhecimento adquirem cada vez mais valor perante toda a sociedade, preparar os indivíduos para que possam lidar eficientemente com os mesmos é fator determinante para a sua inclusão nesse meio. Acima de tudo, capacitar as pessoas informacionalmente é papel imprescindível das instituições de ensino para o pleno desenvolvimento dos estudantes, desde a educação básica. Faz-se necessário que eles sejam instigados a pensar, a desenvolver o raciocínio crítico e a aprender a aprender, desenvolvendo com isso autonomia no processo de identificação da necessidade de informação, na busca, recuperação, leitura, avaliação, interpretação e na produção de novos conhecimentos. Ou seja, essa capacitação informacional é indispensável para que, ao atingir o nível superior, possam suprir as exigências que o ambiente impõe. A expressão competência em informação é um termo derivado dos estudos de Information Literacy (IL), que, segundo a definição da American Library Association (ALA) (1989, apud CAMPELLO; ABREU 2005, p. 179), se traduz pela capacidade de "reconhecer quando uma informação é necessária e [...] ter a habilidade de localizar, avaliar e usar efetivamente a informação".

Dudziak (2003, p. 27) complementa definindo a Information Literacy como:

O processo contínuo de internalização de fundamentos conceituais, atitudinais e de habilidades necessárias à compreensão e interação permanente com 0 universo 
informacional e sua dinâmica, de modo a proporcionar um aprendizado ao longo da vida.

Ela tem como objetivo "[...] formar indivíduos que saibam determinar a natureza e extensão de sua necessidade de informação como suporte a um processo inteligente de decisão" (DUDZIAK, 2003, p. 28).

A informação e o conhecimento são intrinsecamente ligados, uma vez que o conhecimento surge se a informação é bem trabalhada e interpretada; mas para que a mesma possa ser assimilada, é necessário que as pessoas estejam aptas a utilizar a informação em seus mais variados suportes, de forma eficiente, gerando assim novos conhecimentos e subsidiando a tomada de decisões.

A maior dificuldade que se encontra atualmente nas universidades é o ingresso de alunos com sérios problemas de relação com o ambiente informacional, pois, segundo Belluzzo (2004), espera-se que os alunos estejam preparados para usar a informação, porém, devido a deficiências no ensino básico, existem dificuldades para que o período da educação superior possa se desenvolver de forma adequada. No entanto, a problemática da educação básica interfere no desenvolvimento dos estudos no ambiente universitário, como aponta Cavalcante (2006, p. 53):

[...] é na escola que o indivíduo irá conviver com o universo formal educativo, desde os primeiros anos de vida. Lugar onde ocorrerão também, quase sempre, os primeiros contatos com o livro, leitura, biblioteca, pesquisa e socialização do conhecimento. Assim, a qualidade da escola de educação infantil, ensino fundamental e médio se refletirá na educação superior e no resultado de seus estudantes.

Tal afirmação pode ser explicitada se observarmos o nível do ensino médio nacional, com sérias dificuldades no desenvolvimento dos alunos, assim como aponta Varela e Guimarães (2006, p. 2):

O ensino médio, no Brasil, pré-requisito para o Ensino Superior, apresenta resultados que levam a concluir que, no processo de letramento informacional, há fragilidades ainda na organização, disseminação da informação e no domínio das competências de transferência e transcendência para a construção do conhecimento [...].

O processo de desenvolvimento da competência informacional envolve diferentes profissionais, tais como pedagogos, professores e bibliotecários, que devem desenvolver suas ações conjuntamente, tendo como foco o desenvolvimento desta habilidade nos alunos, assim como seu conhecimento e sua formação profissional.

No contexto desta pesquisa foi relevante explicitar os objetivos do projeto pedagógico do Curso de graduação em Biblioteconomia da 
Pontifícia Universidade Católica de Campinas (PUCC), sendo os objetivos gerais (PONTIFÍCIA UNIVERSIDADE CATÓLICA DE CAMPINAS, 2008, p.23):

1. Habilitar o profissional a desenvolver seu trabalho como agente de transformações sociais;

2. Articular-se com outras áreas do conhecimento;

3. Promover a interação das disciplinas pertinentes à área, através da teoria e da prática;

4. Oferecer, através de disciplinas de apoio, uma formação que possibilite ao profissional desempenhar as funções pertinentes a sua área de atuação.

O objetivo específico, ainda de acordo com o projeto pedagógico, é "formar o profissional para atuar na área da informação, tornando-o apto a planejar, desenvolver e oferecer serviços de informação, de forma autônoma"; e se espera que ele "saiba buscar a informação avaliando sempre a necessidade do usuário". Suas atividades relacionadas ao ambiente informacional, e sendo a informação a matéria-prima para o desenvolvimento de suas tarefas, evidenciam que o mesmo é apto para incentivar o desenvolvimento da competência em informação nos alunos.

A vida acadêmica se dará de forma muito mais fácil se os alunos dispuserem de autonomia informacional, pois assim reunirão condições de suprir as exigências do ambiente universitário. Para isso, o estímulo se faz extremamente importante no processo de recuperação da informação, pois será dada importância à informação que precisa ser recuperada, conforme afirma Miranda (2006, p. 103):

A busca e o uso da informação dependem de como o indivíduo avalia a relevância cognitiva e emocional da informação recebida e de atributos objetivos capazes de determinar a pertinência da informação a certa situação problemática.

Por esta razão, as instituições de ensino devem ter a preocupação de elaborar práticas voltadas ao desenvolvimento da competência em informação, o que está de acordo com Cavalcante (2006, p. 56), que afirma:

A elaboração e aplicação de políticas de formação para a competência e uso da informação devem fazer parte das agendas governamentais no campo educacional, gerando bases de compreensão em seus diferentes níveis, para garantir um benefício que se estende para toda a sociedade.

Pode-se, portanto, explicitar a importância da competência informacional, e como tal atributo se faz extremamente pertinente para o desenvolvimento, não apenas pessoal, mas coletivo e da ciência. 


\section{Histórico}

Os estudos acerca da information literacy, segundo Dudziak (2003 p. 24), surgiram pela primeira vez na literatura em 1974, em um relatório intitulado The information service environment relationships and priorities, de autoria do bibliotecário americano Paul Zurkowski.

Em cenário nacional, nota-se que o desenvolvimento do termo information literacy deriva dos estudos de educação de usuários, a partir da atitude de alguns bibliotecários que buscavam ampliar a função pedagógica da biblioteca. De acordo com Dudziak (2003 p. 28), "no Brasil, dadas as devidas proporções, os precursores da information literacy estão entre aqueles bibliotecários que desenvolveram estudos relativos à educação de usuários", sendo que o primeiro curso registrado data de 1955, por Terezine Arantes Ferraz. A autora destaca ainda o trabalho de Luck et al. (2000 apud DUDZIAK 2003, p. 28), que buscou analisar o papel da biblioteca universitária como mediadora no processo pedagógico e curricular. A information literacy tem em seu histórico pesquisas sobre o assunto em um período abrangente, ainda que implicitamente, o que oferece condições propícias para seu desenvolvimento em nível nacional.

\section{Information literacy: em busca de um conceito}

Dudziak (2001, p. 55-56) traz em seu trabalho a definição de diversos autores para o conceito de literacy: Langford (1998) afirma que a literacy foi definida como a habilidade de ler, escrever e compreender; e Lyman (1979, p 196) define literacy como "a habilidade de compreender matérias, ler criticamente, usar materiais complexos, e aprender por si mesmo", e também indica que o conceito de literacy poderá diferir de cultura para cultura.

Diante de tais definições, pode-se entender que este termo engloba diversas concepções, que vão desde o ato de saber ler e escrever, à competência necessária para o desenvolvimento de atividades, no caso com a informação, de sua recuperação e das técnicas para tal, até sua comunicação formal. Dudziak (2002, p. 3) se refere a ele como "alfabetização informacional, letramento, literacia, fluência informacional, competência em informação". No entanto, para que fique claro o termo competência em informação, define-se competência segundo Miranda (2006, p. 107):

Competências seriam características que proporcionam resultados efetivos - incluindo habilidades cognitivas ou intelectuais -, habilidades intrapessoais e habilidades interpessoais. [...] É, também, a iniciativa sob a condição de autonomia, pressupondo a mobilização dos recursos internos pessoais (adquiridos, solicitados e desenvolvidos pelos indivíduos em dada situação) [...]. 
Estas afirmações complementam o que escreveu Belluzzo et al. (2004), esclarecendo a competência em informação:

[...] as tecnologias, o acesso à informação, a compreensão, o conhecimento das fontes de informação, bem como a capacidade de interpretação, síntese, reformulação e comunicação, são processos apoiados em uma perspectiva de solução de problemas, o qual está sendo denominado de competência informacional (information literacy).

Diante de tal afirmação, se faz oportuno explicitar que não existe ainda uma tradução para a expressão, e que sua utilização como competência informacional ocorre por se adequar melhor às várias definições dadas à IL.

Diversos autores buscaram e buscam definir o conceito de IL, dentre os quais Caregnato (2000, p. 28), apontando que a information literacy é uma "expansão do conceito de educação de usuários".

Entretanto, existem afirmações como a de McCrank (1991 apud CAMPELLO 2006, p. 64), que admite "que e os bibliotecários assumiram a expressão, mas encontram dificuldades em chegar a um consenso sobre seu significado", sendo então desenvolvidas as mesmas atividades da educação de usuários com apenas um nome diferente, fazendo marketing da profissão. Campello (2003) trabalha a competência em informação no âmbito da biblioteca escolar, e com Hatschbach (2002, p. 95) temos a afirmação de que as atividades relacionadas à competência em informação tratam "das habilidades acerca do uso da informação em relação à sua busca, localização, avaliação e divulgação, integrando a utilização de novas tecnologias e a capacidade de resolução de problemas de informação". Ou seja, as atitudes desencadeadas pelo desenvolvimento da competência informacional tornam os indivíduos autônomos para a busca e a utilização da informação, capazes de avaliar se a mesma é relevante ou não, produzindo assim novos conhecimentos.

Tais considerações a respeito da tradução correta para o termo information literacy nos expõe um cenário em desenvolvimento no país. Por este fato, este trabalho utiliza a expressão competência informacional, pois, conforme visto anteriormente, este termo melhor de adapta às várias definições propostas.

\section{Comportamento na busca da informação: o modelo de Kuhlthau e a competência informacional}

Percebem-se duas vertentes de estudos em relação aos processos de recuperação da informação. Garcia e Silva (2005) indicam que há o foco nos sistemas de recuperação da informação ou no usuário da informação. Os autores afirmam que "a perspectiva centrada no usuário amplia os limites do Sistema de Recuperação da Informação com a incorporação do componente humano e do ambiente em que acontece a busca por informações" ( $p$. 6). Os estudos de Kuhlthau (1996) se 
enquadram na segunda vertente, pois observam o ser humano na busca de informação e os processos implícitos nesta atividade, e não como os sistemas de recuperação da informação interferem nas pessoas.

De acordo com as informações de Campello e Abreu (2005), os estudos da pesquisadora Carol Kuhlthau (1996) tiveram como objetivo analisar o processo de busca da informação e todas as etapas envolvidas para se obtê-la, avaliando a interferência direta dos sentimentos das pessoas nas etapas da pesquisa. Kuhlthau baseou seus estudos em teorias de aprendizagem e em pesquisas sobre o processo da construção de textos e sobre a reação psicológica das pessoas no desenvolver de seus trabalhos.

Para o desenvolvimento de sua pesquisa, Kuhlthau observou o comportamento de alunos do ensino médio durante o desenvolvimento de trabalhos escolares, e pôde perceber que, mesmo sendo instruídos pelos professores sobre como recuperar o conteúdo necessário, seus sentimentos relacionados à execução daquela tarefa interferiam diretamente no desenvolvimento dela; visto que os alunos que expressavam sentimentos negativos, como ansiedade, acabavam se frustrando. Ao analisar mais detalhadamente a interferência dos sentimentos nas fases de desenvolvimento dos trabalhos, a pesquisadora acabou por desenvolver um modelo de busca da informação, conhecido como Information Search Process - ISP, composto por seis fases, como citado por Campelo e Abreu (2005, p. 180):

a) Início da tarefa: nesse momento os alunos percebem que precisam de informação para realizar o trabalho; expressam sentimentos de incerteza e apreensão; procuram entender o que irão encontrar pela frente $e$ recordar tarefas semelhantes.

b) Escolha do tema: os alunos ficam otimistas depois que conseguem escolher o tema; a escolha é feita em função da possibilidade de sucesso, e é relacionada a fatores tais como o interesse pelo tema e as informações disponíveis.

c) Exploração do tema: significa procurar informação geral sobre o tópico para definir um foco ou um ponto de vista pessoal.

d) Formulação da questão: consiste na escolha de uma abordagem específica para o trabalho; o foco geralmente vai emergindo à medida que o trabalho avança.

e) Coleta de informação: nessa fase o aluno usa o sistema de informação com mais intensidade, para encontrar informações que apóiem suas idéias.

f) Encerramento da tarefa: nessa etapa são comuns os sentimentos de alívio, acompanhados de satisfação, se a busca de informação teve sucesso, e de frustração, caso contrário. 
Buscando uma relação entre o modelo de Kuhlthau e a competência informacional, pôde-se observar que todas as etapas do modelo proposto correspondem aos objetivos da competência informacional. Analisando ambos, nota-se que no início da tarefa os alunos devem identificar suas necessidades de informação e, uma vez capacitados informacionalmente, não apresentam o sentimento de dúvida, sendo capazes de utilizar fontes de informação confiáveis que recuperem a informação pertinente. Isto possibilitaria aos indivíduos tematizar e explorar 0 assunto a ser trabalhado, definindo um foco e avaliando criticamente as informações recuperadas, formulando assim questões que norteiem o desenvolvimento da pesquisa. Este fato desencadeia o desenvolvimento de novas necessidades informacionais, estando eles sempre atentos às suas ações e suas implicações, buscando com isso o desenvolvimento da inteligência e do conhecimento. Coletando as informações pertinentes para dar embasamento ao desenvolvimento de seu trabalho e de suas idéias, os pesquisadores teriam uma postura independente, de aprendizado autônomo, ou seja, seriam aprendizes independentes. O encerramento dos trabalhos possui grande impacto no desenvolvimento dos sentimentos das pessoas, pois, se obtiveram um bom resultado, os sentimentos podem ser de alívio e satisfação; ou o contrário, se o resultado obtido não foi o esperado. No entanto, os resultados obtidos no desenvolvimento dos trabalhos proporcionam aos seus autores a experiência necessária para seguir determinado caminho ou não, para o desenvolvimento de futuras pesquisas, proporcionando assim aos indivíduos a capacidade de aprender ao longo da vida.

\section{Objetivos, metodologia e coleta de dados}

Para verificar se a formação oferecida pela Universidade (PUCC) no Curso de Biblioteconomia vem sendo compatível com os objetivos de seu projeto pedagógico, fez-se relevante identificar a contribuição do referido curso no desenvolvimento da competência em informação de seus alunos, observando qual o nível desta habilidade nos ingressantes e explicitando o aprimoramento de tal atributo nos formandos. Ao observar tais características, foi possível indicar como o processo de capacitação do Curso Universitário confere aos alunos as habilidades para o exercício da profissão, e, a partir disso, qual é o cenário atual da competência informacional dos alunos da Faculdade de Biblioteconomia (FABI), verificando ainda como os mesmos utilizaram as habilidades informacionais em seus trabalhos.

O levantamento de dados para a o desenvolvimento desta pesquisa foi obtido a partir de revisão literária e também da aplicação de um questionário aos alunos ingressantes e formandos em 2008, relacionados com atividades de pesquisa acadêmica e atividades de recuperação da informação. Os resultados obtidos foram analisados sob a ótica do modelo proposto por Kuhlthau (1996) e posteriormente comparados à pesquisa de Campello e Abreu (2005), para evidenciar as diferenças contextuais e como as mesmas interferem nos resultados, e 
também para perceber de forma geral como as universidades vêm trabalhando a questão do desenvolvimento da competência informacional em seus alunos, especificamente alunos de biblioteconomia, para 0 exercício da profissão. Por fim, os resultados revelaram se os objetivos propostos no projeto pedagógico do Curso de Biblioteconomia estão sendo atingidos.

\section{Análise dos resultados}

Após analisar os dados levantados e compará-los aos do trabalho de Campello e Abreu (2005), pôde-se evidenciar que as maiores dificuldades entre os alunos de ambas as turmas são organizar as idéias e aplicar um foco para o desenvolvimento do trabalho, assim como desenvolver e estruturar as idéias na redação final do mesmo. Verifica-se, então, a necessidade de um melhor planejamento por parte das instituições de ensino, para que estas dificuldades possam ser superadas, e para que assim os alunos tenham um maior aproveitamento e desenvolvimento durante o período de estudos. Segundo a opinião dos discentes, tal característica existe pelo fato de que no ensino médio "não havia estímulo por parte dos professores" e "por não ligar os assuntos tratados à realidade e não buscar capacitar os alunos para a busca das informações". Isto nos aponta o cenário atual da competência informacional dos alunos da Faculdade, explicitando que para a maioria dos alunos a contribuição do Ensino médio é pequena, portanto os discentes ingressam no nível superior sem as habilidades e competências necessárias. Tal fato indica um cenário em que os alunos necessitam de determinada atenção, por parte da coordenação pedagógica, para o desenvolvimento de atributos que já deveriam ter sido desenvolvidos. Por isso, fica explícito que a participação do professor se torna de extrema importância, uma vez que a interação deste profissional com a realidade dos alunos define os sentimentos no início e no desenvolver do trabalho, o que acarreta boas perspectivas e ações por parte dos estudantes, ou o contrário.

Identificou-se a pouca participação do bibliotecário, em ambos os casos, visto que os alunos buscaram seu auxílio apenas nas fases finais do trabalho, e, neste contexto, percebe-se a necessidade de uma melhor atuação por parte deste profissional, explicitando suas competências e habilidades. Especial atenção deve ser dada, neste caso, aos alunos ingressantes, pois estes podem considerar dispensável a participação do bibliotecário no processo da busca informacional, sem estarem, de fato, exercendo autonomia.

Comparando-se os dados obtidos com os da pesquisa de Campello e Abreu (2005), sob a ótica do modelo de Kuhthau (1996), obtém-se a confirmação do modelo proposto de Kuhlthau, que indica forte influencia psicológica nas atitudes dos alunos; o que fica claro com a resposta de um dos discentes: "Inicialmente surgiram as dúvidas, pois não conhecia o tema, mas na medida em que eu recuperava informações sobre o mesmo, os sentimentos evoluíram para otimista, e confiante. Pelo fato de conseguir desenvolver o trabalho e ter as informações sobre o 
tema em mãos e finalmente obter a conclusão o sentimento mudou para satisfeito".

Os resultados de ambas as pesquisas explicitaram a necessidade de maior atenção a todo o contexto dos estudantes, assim como um maior cuidado dos docentes na orientação dos discentes; e indicaram ainda a necessária participação do bibliotecário, enquanto educador e propulsor do desenvolvimento da competência informacional. A confirmação do modelo indica as etapas do processo de pesquisa que melhor precisam ser trabalhadas, que reproduzem a maior deficiência na competência informacional dos alunos; ou seja, a identificação das reais necessidades de informação para dar início ao trabalho com boas perspectivas e sentimentos, assim como a etapa final de elaboração do texto.

Ao se analisar se o Curso de Biblioteconomia vem atingindo os objetivos propostos em seu projeto pedagógico, pôde-se observar que os alunos devem ser mais instigados a desenvolver suas ações como agentes de transformação social, uma vez que eles não reconheceram no bibliotecário as habilidades para auxiliá-los em suas dificuldades com o ambiente informacional, pois recorreram a ele somente em último caso. A partir dos dados levantados, pôde-se observar que o curso oferece a seus alunos a oportunidade de desenvolvimento das habilidades básicas para o exercício da profissão, tais como, segundo a opinião dos próprios alunos, o raciocínio crítico, a recuperação eficaz da informação e a autonomia. Para os alunos do primeiro ano, a autonomia é o fator mais explícito de desenvolvimento, já para os formandos a característica mais desenvolvida é o raciocínio crítico. Procurando entender tais posicionamentos, pode-se pensar que, ao ingressar na Universidade, o maior impacto para os ingressantes é de fato a autonomia, o que não ocorre nas fases anteriores de estudo; e para os formandos, que já estão neste ambiente há quatro anos, portanto adaptados, o maior impacto é o raciocínio crítico, competência indispensável para a última etapa da formação. Evidencia-se, por fim, que o Curso vem atribuindo a seus alunos as habilidades necessárias para o exercício da profissão, porém cabe ressaltar que cada discente deve ser pró-ativo e buscar, para além da sala de aula, desenvolver conhecimentos e habilidades necessários à profissão. Observa-se, assim, que o curso de Biblioteconomia da PUCC desenvolve em seus alunos tais características, não apenas por incentivar o raciocínio crítico ou o desenvolvimento da autonomia, mas por trabalhar desde o primeiro semestre a importância da informação.

Verificou-se, também, que há a interdisciplinaridade com outras áreas do conhecimento, visto que muitos dos docentes do Curso não são oriundos da Biblioteconomia e da Ciência da Informação. Com a presente pesquisa, pôde ser observado que a interação entre as disciplinas da Faculdade contribui muito para o desenvolvimento da competência informacional, porém os profissionais bibliotecários não fazem parte desta atividade, ficando isto a critério dos próprios docentes, sendo este um aspecto que precisa ser mais bem trabalhado. Especificamente os objetivos do projeto pedagógico vêm sendo atingidos, pois os profissionais 
que se formam saem aptos a atuar na área de informação, planejando e gerenciando as atividades e serviços pertinentes de forma autônoma, sempre de acordo com as necessidades de seu público usuário.

Ao verificar os objetivos propostos na presente pesquisa, foram observadas as seguintes conclusões: para os alunos ingressantes e formandos em 2008, a contribuição do Curso de Biblioteconomia se faz evidente, visto que para a maioria deles a Faculdade oferece as oportunidades necessárias para o desenvolvimento da competência informacional, necessitando apenas de se atentar às principais dificuldades dos mesmos.

Pôde-se observar que a maior evidência da capacitação profissional dos discentes está no fato de que os alunos entram desprovidos da competência informacional, habilidade básica para o profissional bibliotecário, e se formam com a consciência da importância deste atributo, verificando uma melhora significativa nesta habilidade. Formamse munidos do conhecimento técnico para a recuperação pertinente da informação, sua análise e posterior desenvolvimento crítico das idéias, sendo então este o cenário da competência informacional dos alunos em 2008.

Durante o desenvolvimento dos trabalhos, pôde-se observar, na prática, como os alunos utilizam a competência informacional, e foi verificado que eles dispõem de certa habilidade quando entram na Universidade, pois explicitaram constantemente a preocupação em recuperar conteúdos pertinentes para a realização de seus trabalhos.

Campello e Abreu (2005) indicaram a necessidade de novas práticas para apoiar o desenvolvimento da competência informacional em seus usuários, principalmente nos futuros profissionais da informação; Possobon et al. (2005) explicitaram a necessidade de ações efetivas para capacitar informacionalmente os alunos; e Rocha (2008) afirmou ser necessário tornar mais amplo o processo de capacitação em informação, uma vez que os alunos podem ser competentes apenas em um foco. Assim, podemos afirmar que a conclusão do estudo desenvolvido na Faculdade de Biblioteconomia da PUCC não diverge das conclusões a que chegaram as pesquisas já desenvolvidas. É importante que novas práticas sejam aplicadas, práticas estas que abarquem todo o contexto de seus estudantes e que visem de fato o desenvolvimento de suas habilidades informacionais em qualquer foco ou contexto. A participação dos bibliotecários, agindo juntamente com os docentes, é uma necessidade primordial para que os alunos tenham a oportunidade de visualizar a atuação do bibliotecário, além da biblioteca.

\section{Considerações finais}

O desenvolvimento desta pesquisa pôde evidenciar como a influência psicológica interfere nas atitudes dos alunos, e explicitou que as atitudes dos docentes, bibliotecários e demais profissionais envolvidos, devem estar voltadas para além do desenvolvimento de habilidades que já 
deveriam ter sido trabalhadas, para ocasionar sentimentos positivos, que se reflitam em suas atitudes.

De fato, a participação do profissional bibliotecário nestas atividades é indispensável, pois o mesmo pode contribuir de forma significativa para o desenvolvimento de sentimentos de confiança nos alunos, auxiliando na recuperação de informações pertinentes, e ensinando técnicas e métodos de busca, seleção e assimilação das informações, que se tornarão um novo conhecimento.

Com o presente estudo, foi possível verificar que o Curso de Biblioteconomia da PUC-Campinas contribui muito para o desenvolvimento da competência informacional nos alunos, e também cumpre com os objetivos propostos em seu projeto pedagógico. Pôde ser evidenciado que os alunos necessitam de apoio em todas as fases do estudo, porém uma atenção especial deve ser dada aos ingressantes, pois, conforme os mesmos apontaram, "tudo que é novo nos amedronta", e os sentimentos negativos interferem em suas ações. Isso não quer dizer que os alunos veteranos não necessitam de apoio, mas salienta que os mesmos desenvolvem suas habilidades informacionais no decorrer do curso universitário.

Observou-se com determinada ênfase que, mesmo a universidade preparando os alunos para trabalharem eficientemente com a informação, os mesmos não são instigados a procurar um profissional bibliotecário para a recuperação das informações, o que não demonstra seu potencial educador e colaborador no desenvolvimento da competência informacional.

Existe a preocupação em proporcionar um exímio aprendizado aos alunos; porém, a aplicação de técnicas voltadas à realidade dos alunos, visando o desenvolvimento da competência informacional, pode favorecer um grande desenvolvimento dos mesmos, o que por sua vez pode ocasionar um gradual aumento de bibliotecários empenhados para que haja o desenvolvimento, em seus usuários, de uma habilidade indispensável nos dias atuais e futuros: a competência informacional.

\section{Referências}

AMERICAN LIBRARY ASSOCIATION. Presidential Committee on Information Literacy. Final report. Chicago, 1989. apud CAMPELLO, B.; ABREU, V. L. F. G. Competência informacional e formação do bibliotecário. Perspectivas em Ciência da Informação, Belo Horizonte, v.10, n.2, p. 178193, 2005.

BELLUZZO, R. C. B. et al. Capacitação do bibliotecário como mediador do aprendizado no uso de fontes de informação. Revista Digital de Biblioteconomia e Ciência da Informação, Campinas, v. 2, n. 1, p. 1-16, jul./dez. 2004.

BELLUZZO, R. C. B. Formação contínua de professores do ensino fundamental sob a ótica do desenvolvimento da Information Literacy, competência indispensável ao acesso à informação e geração do 
conhecimento. Transinformação, Campinas, v. 16, n. 1, p. 17-32, jan./abr. 2004.

CAMPELLO, B. O movimento da competência informacional: uma perspectiva para o letramento informacional. Ciência da Informação, Brasília, v. 32, n. 3, p. 28-37, set/dez. 2003. Disponível em: <http://www.scielo.br/pdf/ci/v32n3/19021.pdf>. Acesso em: 10 out. 2007.

A escolarização da competência informacional. Revista Brasileira de Biblioteconomia e Documentação: Nova série, São Paulo, v. 2, n. 2, p. 63-77, dez. 2006.

CAMPELLO, B.; ABREU, V. L. F. G. Competência informacional e formação do bibliotecário. Perspectivas em Ciência da Informação, Belo Horizonte, v.10, n.2, p. 178-193, 2005.

CAREGNATO, S. E. O desenvolvimento de habilidades informacionais: o papel das bibliotecas universitárias no contexto da informação digital em rede. Revista de Biblioteconomia \& Comunicação, Porto Alegre, v. 8, p. 47-55, jan./dez. 2000.

CAVALCANTE, L. E. Políticas de formação para a competência informacional: o papel das universidades. Revista Brasileira de Biblioteconomia e Documentação: Nova série, São Paulo, v. 2, n. 2, p. 4762, dez. 2006.

DUDZIAK, E. A. Information literacy education: integração pedagógica entre bibliotecários e docentes visando a competência em informação e o aprendizado ao longo da vida. 2001. Disponível em: <http://www.sibi.ufrj.br/snbu/snbu2002/oralpdf/47.a.pdf>. Acesso em: 10 out. 2007.

- A information literacy e o papel educacional das bibliotecas. 2001. 187f Dissertação (Mestrado em Ciências da Comunicação) - Escola de Comunicações e Artes-Universidade de São Paulo, São Paulo, 2001.

- Information Literacy e o papel educacional das bibliotecas e do bibliotecário na construção da competência em informação. In: CONGRESSO ANUAL EM CIÊNCIA DA COMUNICAÇÃO, 25., Salvador/BA, Anais... Salvador: ENDOCOM, 05 set. 2002.

Information literacy: princípios, filosofia e prática. Ciência da Informação, Brasília, v. 32, n. 1, p. 23-35, abr. 2003. Disponível em <http://www.scielo.br/scielo.php?script=sci_arttext\&pid=S010019652003000100003 \&lng=pt\&nrm=iso >. Acesso em: 07 out. 2007.

GARCIA, R. M.; SILVA, H. C. O comportamento do usuário final na recuperação temática da informação: um estudo com pós-graduandos da UNESP de Marília. DataGramaZero - Revista de Ciência da Informação, v. 6, n. 3, p.12-56, jun.2005. 
HATSCHBACH, M. H. L. Information literacy: aspectos conceituais e iniciativas em ambiente digital para o estudante de nível superior. 2002. 109 f. Dissertação (Mestrado em Ciência da Informação) - Universidade Federal do Rio de Janeiro, Rio de Janeiro, 2002.

KUHLTHAU, C. C. Seeking meaning a process approach to library and information services. Norwood, N.J.: Ablex, 1996.

LANGFORD, L. Information literacy: a classification. School Libraries World Wilde, v. 4, n. 1, p. 59-72, 1998. apud DUDZIAK, E. A. A information literacy e o papel educacional das bibliotecas. 2001. 187f Dissertação (Mestrado em Ciências da Comunicação) - Escola de Comunicações e Artes-Universidade de São Paulo, São Paulo, 2001.

LUCK, E. H. et al. (2000). A biblioteca universitária e as diretrizes curriculares do ensino de graduação. In: SIMPÓSIO BRASILEIRO DE BIBLITOECAS UNIVERSITÁRIAS, 11., Florianópolis. 2000. Anais. Florianópolis, UFSC. apud DUDZIAK, E. A. Information literacy: princípios, filosofia e prática. Ciência da Informação, Brasília, v. 32, n. 1, p. 23-35, abr. 2003. Disponível em <http://www.scielo.br/scielo.php?script=sci_arttext\&pid=S010019652003000100003 \&lng=pt\&nrm=iso >. Acesso em: 07 out. 2007.

MCCRANK, L. J. Information Literacy: a bogus bandwagon? Library Journal, v. 116, n. 8, p.38-42, May 1 1991. apud CAMPELLO, B. A escolarização da competência informacional. Revista Brasileira de Biblioteconomia e Documentação: Nova série, São Paulo, v. 2, n. 2, p. 6377, dez. 2006.

LYMAN, L. Literacy education as Library community service. Library Trends, v. 28, n. 2, p. 193-217. apud DUDZIAK, E. A. A information literacy e o papel educacional das bibliotecas. 2001. 187f Dissertação (Mestrado em Ciências da Comunicação) - Escola de Comunicações e Artes-Universidade de São Paulo, São Paulo, 2001.

MIRANDA, S. V. Como as necessidades de informação podem se relacionar com as competências informacionais. Ciência da Informação, Brasília, v. 35, n. 3, p. 99-114, set./dez. 2006.

PONTIFÍCIA UNIVERSIDADE CATÓLICA DE CAMPINAS. Projeto políticopedagógico do curso de Biblioteconomia. Campinas: [s. n.], 2008. 24p.

POSSOBON, K. R. et al. Alfabetização informacional: um estudo do nível de competências dos calouros do Curso de Biblioteconomia da Universidade Federal do Rio Grande do Sul. In: CONGRESSO BRASILEIRO DE BIBLIOTECONOMIA, DOCUMENTACAO E CIENCIA DA INFORMACAO, 21., 17- 22 jul. 2005, Curitiba. Anais... Curitiba: CBBD, 2005.

ROCHA, E. C. F. Competência informacional de formandos em Sistemas de Informação. In: ENANCIB - ENCONTRO NACIONAL DE PESQUISA EM CIÊNCIA DA INFORMAÇÃO, 9., 2008, São Paulo. Anais... São Paulo: USP, 
2008. Disponível em: <http://www.enancib2008.com.br/cd/6\%20\%20Trabalhos\%20em\%20PDFGT6/2\%20-\%20Poster/1854\%20-

\%20Compet\%C3\%AAncia\%20informacional\%20de\%20formandos\%20em \%20Siste\%E2\%80\%A6.pdf> Acesso em: 25 out. 2008.

SEABRA, C. Uma nova educação para uma nova era. In: DOWBOR, L. et al. (org.) Desafios da globalização. Petrópolis: Vozes, 1998. apud DUDZIAK, E. A. A information literacy e o papel educacional das bibliotecas. 2001. 187f Dissertação (Mestrado em Ciências da Comunicação) - Escola de Comunicações e Artes-Universidade de São Paulo, São Paulo, 2001.

VARELA, A. V.; GUIMARÃES, I. Apreensão e construção do conhecimento científico: descompasso entre necessidades informacionais e pensamento crítico. Liinc em Revista, v. 2, n. 2, p. 120-133, set. 2006. Disponível em: $<$ www.ibict. br/liinc/include/getdoc. php?id =201\&article $=30 \&$ mode $=$ pdf $>$. Acesso em 25 out. 2008.

\section{APÊNDICE 1 - Questionário}

Prezado Aluno (a),

Solicito, por favor, que responda ao questionário que segue abaixo e que foi baseado no trabalho de Campello e Abreu (2005).

Desde já, agradeço pela sua colaboração.

Atenciosamente,

O autor.

Desenvolvimento da competência em informação no período da graduação do Curso de Biblioteconomia da PUC-Campinas: uma análise em 2008

Belluzzo et al. (2004) conceitua a competência informacional como sendo as habilidades relativas ao

[...] acesso à informação, a compreensão, o conhecimento das fontes de informação, bem como a capacidade de interpretação, síntese, reformulação e comunicação, [...] o qual está sendo denominado de competência informacional (information literacy).

1 - Esta é sua primeira graduação?

2 - De acordo com a sua experiência, aponte qual a maior diferença entre a forma em que desenvolvia seus trabalhos no ensino médio e como você desenvolve atualmente na Universidade:

( ) estratégias nas buscas bibliográficas

( ) acesso a literatura

( ) autonomia no processo de elaboração do trabalho

( ) inclusão de conteúdos complementares

( ) comentários críticos acerca do conteúdo

( ) comparação entre autores 
outra.

( ) fontes de informação disponíveis

3 - O ensino médio contribuiu para o desenvolvimento de sua competência informacional:

( ) muito

( ) pouco

( ) não contribuiu

Explique

4 - Após o período de estudos na Universidade, como você vê o desenvolvimento de sua competência em informação? Você percebe melhorias em seu comportamento de busca da informação? Explique.

5- A forma que as disciplinas do Curso interagem entre si, colabora (colaborou) para o desenvolvimento de sua competência informacional? Comente.

6- Na condição de aluno da Faculdade, qual é o nível de contribuição do curso para o desenvolvimento e/ou aprimoramento de suas competências informacionais:
( ) muito
( ) pouco
( ) não vem contribuindo
Explique

7- indique 0 fator pessoal que mais demonstra atualmente 0 desenvolvimento de sua competência informacional?

( ) Raciocínio crítico

( ) Recuperação da informação

( ) Autonomia

Outros:

(

Responda às questões abaixo com base em um trabalho acadêmico individual

8 - Qual foi o período do curso em que o trabalho foi feito?

9 - Qual foi o tema?

10 - Já o conhecia?

11- a) Houve auxílio do professor na indicação de bibliografia? 
b) Se sim, você utilizou apenas a bibliografia indicada ou buscou novas referências?

c) Onde realizou a busca bibliográfica?

12- Você acrescentou algum conteúdo além do solicitado pelo professor? Por quê? trabalho?

13- Qual a primeira atitude tomada para o desenvolvimento do

14- No início de seu trabalho, você buscou orientação?

(Pode marcar mais de um item).

( ) com o professor

( ) com colegas de classe

( ) com outros colegas

( ) com outra pessoa. Quem?

15- Assinale em ordem prioritária (onde 1 é o mais importante), os itens que melhor representam suas atitudes para desenvolver o trabalho:

( ) discutiu sobre o assunto do trabalho

( ) pediu ajuda ao bibliotecário

( ) consultou o catálogo da universidade

( ) consultou a base de periódicos

( ) foi direto às estantes

( ) escolheu um enfoque / abordagem para desenvolver o assunto

( ) tirou dúvidas com pessoas que conhecem o tópico

( ) consultou obras de referência

( ) consultou bases de dados

( ) organizou uma lista de tópicos a serem incluídos no trabalho

( ) discutiu com outras pessoas

16- Para você, o tema foi considerado complexo?

( ) Sim

Por quê?

( ) Não

Por quê?

17- Você normalizou este trabalho (utilizou as normas da ABNT)? Qual foi a maior dificuldade para tal?

18- Qual foi a maior dificuldade para a realização do referido trabalho?

( ) Identificar as necessidades de informação

( ) buscar e recuperar informação

( ) ler e interpretar as informações

( ) produzir e estruturar a redação final do trabalho 
( ) Outra:

19 - a)Como você se sentiu diante da necessidade de desenvolver o referido trabalho? (Pode marcar mais de um item).

( )Confiante ( )Frustrado

( )Confuso ( )Otimista

( )Inseguro ( )Com dúvidas

( )Seguro ( )Satisfeito

( )Outros:

b) Esses sentimentos surgiram por qual motivo?

20- a) Qual foi o seu sentimento quando você terminou seu trabalho?

(Pode marcar mais de um item)

( )Confiante

( )Frustrado

( )Confuso

( )Otimista

( )Inseguro

( )Com dúvidas

( )Seguro

( )Satisfeito

( )Aliviado

( ) Outros:

b) Por quê?

21. Ao final do trabalho, você considera que aprendeu sobre o assunto e formou opinião pessoal? Comente.

22. Comentário livre: 